\title{
Whiplash: diagnosis, treatment, and associated injuries
}

\author{
Sanjay Yadla $\cdot$ John K. Ratliff · James S. Harrop
}

Published online: 6 November 2007

(C) Humana Press 2007

\begin{abstract}
Study design Focused review of the current literature. Objective To identify and synthesize the most current data pertaining to the diagnosis and treatment of whiplash and whiplash-associated disorders (WAD), and to report on whiplash-related injuries. Methods A search of OVID Medline (1996-January 2007) and the Cochrane database of systematic reviews was performed using the keywords whiplash and WAD. Articles under subheadings for pathology, diagnosis, treatment, and epidemiology were chosen for review after identification by the authors. Results A total of 485 articles in the English language literature were identified. Thirty-six articles pertained to the diagnosis, treatment, epidemiology of whiplash, and WAD, and were eligible for focused review. From these, 21 primary and 15 secondary sources were identified for full review. In addition, five articles were found that focused on whiplash associated cervical injuries. These five articles were also primary sources. Conclusions Whiplash is a common injury associated most often with motor vehicle accidents. It may present with a variety of clinical manifestations, collectively termed WAD. Whiplash is an important cause of chronic disability. Many controversies exist regarding the diagnosis and treatment of whiplash injuries. The multifactorial etiology, believed to underly whiplash injuries, make management highly variable between patients. Radiographic evidence of injury often cannot be identified in the acute phase. Recent studies suggest early mobilization may lead to improved outcomes. Ligamentous and bony injuries may go undetected at initial
\end{abstract}

S. Yadla $(\bowtie)$ J J. K. Ratliff · J. S. Harrop

Department of Neurological Surgery, Thomas Jefferson

University Hospital, 909 Walnut Street, 3rd Floor, Philadelphia, PA 19107, USA

e-mail: sanjay.yadla@mail.tju.edu presentation leading to delayed diagnosis and inappropriate therapies.

Keywords Whiplash .

Whiplash associated disorders (WAD) .

Cervical spine injury

\section{Introduction}

The Quebec task force (QTF) on whiplash associated disorders (WAD) defined whiplash as "bony or soft tissue injuries" resulting "from rear-end or side impact, predominantly in motor vehicle accidents, and from other mishaps" as a result of "an acceleration-deceleration mechanism of energy transfer to the neck" [1]. Whiplash is associated with a wide variety of clinical manifestations including neck pain, neck stiffness, arm pain and paresthesias, problems with memory and concentration, and psychological distress. This group of symptoms and signs are collectively termed WAD. The QTF developed a classification system for WAD based on severity of signs and symptoms (Table 1).

Whiplash is the most common injury associated with motor vehicle accidents, affecting up to $83 \%$ of patients involved in collisions, and is a common cause of chronic disability [2, 3]. The overall economic burden of whiplash injury, including medical care, disability, and sick leave, is estimated at \$3.9 billion annually in the US [4]. If litigation is included, the costs are greater than $\$ 29$ billion [5]. The incidence of WAD is widely variable in the literature. In the US, it is estimated at 4 per 1,000 persons [6].

The most recent literature suggests that whiplash injury may occur as a result of hyperextension of the lower cervical vertebrae in relation to a relative flexion of the upper cervical vertebrae, which produces an S-shape of the 
Table 1 QTF classification of whiplash-associated disorders ${ }^{1}$

\begin{tabular}{ll}
\hline Grade & Classification \\
\hline 0 & No complaint about the neck. No physical signs \\
I & $\begin{array}{l}\text { Neck complaint of pain, stiffness or tenderness only. } \\
\text { No physical signs }\end{array}$ \\
II $\quad \begin{array}{l}\text { Neck complaint and musculoskeletal signs. Musculoskeletal } \\
\text { signs include decreased range of motion } \\
\text { and point tenderness }\end{array}$ \\
III $\quad \begin{array}{l}\text { Neck complaint and neurological signs. Neurological } \\
\text { signs include decreased or absent deep tendon reflexes, } \\
\text { weakness and sensory deficits }\end{array}$ \\
IV $\quad$ Neck complain and fracture or dislocation
\end{tabular}

1 Adopted from Ref. [1]

cervical spine at the time of impact [7]. This differs from the normal physiology where motion of the cervical spine begins with the upper vertebrae. This theory suggests an abnormal physiologic basis for the development of whiplash injuries.

The current review provides a summary of recent literature focused on the diagnosis and treatment of whiplash injury and WAD. In addition, we offer a focused review of whiplash associated cervical injuries including ligamentous injury, loss of lordosis, and fractures of the superior articulating facet.

\section{Methods}

A search of OVID Medline (1996-January 2007) and the Cochrane database of systematic reviews was performed using the keywords whiplash and WAD. Articles under subheadings for pathology, diagnosis, treatment, and epidemiology were chosen for review after identification by the authors. Additional sources not identified by the primary search were obtained by cross-referencing bibliographies.

\section{Results}

A total of 485 articles published from 1996 to 2006 in the English language were found. Thirty-six articles were identified for focused review pertaining to the diagnosis, treatment, and epidemiology of whiplash and WAD. Twenty-one primary sources were identified, and $15 \mathrm{sec}-$ ondary sources were identified for review. In addition, five articles were identified that focused on whiplash associated cervical injuries. All five articles were primary sources.

\section{Discussion}

Many controversies exist regarding the diagnosis, treatment, and prognosis of whiplash injuries. The wide variety in the number of patients reporting injury and the inability in many cases to find firm diagnostic evidence of injury has led many to question the authenticity of whiplash injury and WAD [8].

\section{Clinical diagnosis}

The diagnosis of whiplash remains clinical. The mechanism of injury must be elicited. The clinical syndrome of whiplash and WAD includes neck pain or stiffness, arm pain and paresthesias, temporomandibular dysfunction, headache, visual disturbances, memory and concentration problems, and psychological distress. There are no specific neuropsychological studies or electrophysiological tests that can diagnose whiplash injury [9].

A wide variety of psychosocial symptoms may be associated with whiplash including depression, anger, fear, anxiety, and hypochondriasis [10]. A so-called whiplash profile has been described, which includes high scores on subscales of somatization, depression, and obsessivecompulsive behavior in patients with WAD [8].

\section{Radiographic diagnosis}

Injury most often is not identified radiographically in the acute phase [10]. A prospective study of 100 patients with normal plain radiography and no neurologic deficit evaluated MRI findings of the brain and cervical spine within 3 weeks of injury [11]. Only one patient had findings associated with trauma (prevertebral edema).

The most common radiographic findings associated with whiplash injury are preexisting degenerative disease or slight loss of the normal lordotic curve of the cervical spine [4]. Flexion-extension X-rays at the time of injury may also reveal a kyphotic angle. It is postulated that this is due to hypermobility at a level adjacent to a level of hypomobility, secondary to muscle spasm [9].

A prospective study of 39 patients with grade two to three whiplash injury who underwent MRI within a mean of 11 days from injury and a follow-up MRI after two years found that $33 \%$ (13 patients) had medullary or dural impingement by cervical discs [12]. At two year followup, all patients with medullary impingement (seven patients) had persistent or increased symptoms and three patients with no or slight changes on MRI had persistent symptoms.

At the time of initial presentation, MRI is not indicated because of high false positive results. CT and MRI are generally reserved for patients with suspected disc or spinal cord injury, fracture, or ligamentous injury. CT and MRI may also be indicated in patients with long term persistent 
arm pain, neurologic deficits, or clinical signs of nerve root compression [10].

\section{Treatment in the acute setting}

Whiplash injuries are difficult to treat for many reasons. Patients may have subjective complaints of pain or paresthesias without any radiologic or clinical evidence of injury. Complex interactions of psychosocial, legal, and physical factors make effective treatment highly variable among different patients. Initial treatment has traditionally included a soft cervical collar to restrict cervical range of motion. More recent studies suggest, however, that early mobilization may lead to improved outcomes and that rest and motion restriction may hinder recovery [13].

Rosenfeld et al. followed 97 patients exposed to whiplash trauma over a three year period prospectively. The patients were randomized either to an early intervention using frequent active cervical rotation or to a standard intervention of initial rest, recommended soft collar, and gradual self-mobilization. Patients who received active intervention had significantly reduced pain intensity and sick leave at 6 months and 3 years respectively [14]. In addition, patients receiving early active intervention had a total cervical range of motion similar to that of matched uninjured controls at 3 year follow-up.

Other investigations have focused on medical interventions at the time of presentation with data extrapolated from spinal cord injury studies. A randomized, placebocontrolled study evaluated the efficacy of high dose steroids given within $8 \mathrm{~h}$ of injury. In this study, treatment subjects received a bolus dose of $30 \mathrm{mg} / \mathrm{kg}$ per hour given over $15 \mathrm{~min}$ followed by a $23 \mathrm{~h}$ maintenance dose of $5.4 \mathrm{mg} / \mathrm{kg}$ per hour [15]. Patients were followed over a 6 month period. Those receiving steroid therapy had significantly fewer total sick days, and fewer disabling symptoms compared to controls.

Treatment in the chronic phase

The QTF review did not report on evidence regarding the independent benefit of exercise in chronic WAD. Studies of patients with chronic neck pain, not necessarily motor vehicle related, suggest that exercise and mobilization may improve long-term outcomes.

A prospective uncontrolled study of patients with Type I and Type II whiplash followed patients through a multimodal treatment program including exercise, group therapy, and occupational therapy. Vendrig et al. found that at 6 month follow-up, $65 \%$ of subjects reported complete return to work, $92 \%$ reported partial or complete return to work, and $81 \%$ reported no medical or paramedical treatments over 6 months [16].

Bunketorp et al. analyzed 47 patients involved in an ongoing randomized controlled trial. Multiple regression analysis found that self-efficacy, a measure of how well an individual believes he can perform a task or specific behavior and emotional reaction in stressful situations, was the most important predictor of persistent disability in patients with WAD [17].

The use of cervical radiofrequency neurotomy (CRFN), a neuroablative procedure used to interrupt nociceptive pathways, has been supported by several studies in patients with chronic WAD. Prushansky et al. conducted a prospective study of 40 patients with chronic whiplash injuryassociated disorders who underwent CRFN treatment. The authors found an improvement in $70 \%$ of patients based on a number of parameters including Neck Disability Index and cervical range of motion [18].

Many other therapeutic interventions have been suggested including temperomandibular joint treatment, cervical traction, intraarticular corticosteroids, and botulinim toxin. The QTF concluded that scientifically rigorous evidence to support their use is currently lacking [1].

\section{Prognosis}

Studies of long-term outcome for patients with whiplash and WAD offer widely variable rates of recovery. Most studies suggest persistent symptoms in $25-40 \%$ of patients after 1 year [9]. Other studies have reported symptoms in as high as $39.6 \%$ of patients as far as 7 years after injury [9].

A number of factors have been consistently associated with delayed recovery including female gender, older age, initial intensity of neck pain, neurologic deficit, preexisting neck pain [19]. In a retrospective cohort study from Dufton et al., several factors associated with minimal clinical change from initial presentation to follow-up were identified. These included older age, female gender, higher initial pain intensity, lawyer involvement, and work status at time of follow-up [19].

The variability in recovery in WAD is a source of considerable controversy. The multivariable nature of WAD suggests that further investigations of clinical, demographic, and psychological factors are warranted in order to improve treatment outcomes.

Whiplash associated cervical injuries

The QTF report focuses on patients with WAD Grade I through III injuries following a motor vehicle collision. 
Grade IV injuries, which include patients with neck complaints and fracture or dislocation, were not specifically addressed. The literature is peppered with case reports of patients with WAD and missed fractures on presentation [4]. The most common radiographically identified abnormalities are loss of cervical lordosis and spondylotic changes [4].

Nyunt reported a single case of a missed superior articular facet of the seventh cervical vertebrae. The patient had been involved in a motor vehicle accident 7 years prior to presenting with transient tetraparesis [20]. A case series of four patients with chip fractures of cervical superior articular facet and cervical radiculopathy reported excellent outcomes after posterior fixation [21].

\section{Conclusions}

Whiplash and WAD are a common and costly burden on the health care system. Associated disabilities and absence from work create a large impact on economic productivity. Diagnosis of these injuries can be difficult for the practitioner and frustrating for the patient. The most recent literature suggests that whiplash injury may occur as a result of hyperextension of the lower cervical vertebrae in relation to a relative flexion of the upper cervical vertebrae.

Treatment can be delayed and confused by multiple social, economic, and psychologic factors. Recent literature suggests that early mobilization and return to activity may offer the best chance for recovery. Still, a highly variable rate of recovery is reported in the literature. The absence of clear diagnostic and treatment options for this common medical problem suggest that further research is duly warranted.

\section{References}

1. Spitzer WO, et al. Scientific monograph of the Quebec task force on whiplash-associated disorders: redefining "Whiplash" and its management. Spine 1995;8S:1S-73S.

2. Cote PDC, Hogg-Johnson S, et al. Initial patterns of clinical care and recovery from whiplash injuries. Arch Intern Med 2005; 165:2257-63.
3. Cote PDC, Cassidy JDDC, et al. A systematic review of the prognosis of acute whiplash and a new conceptual framework to synthesize the literature. Spine 2001;26:E445-8.

4. Eck JC, Hodges SD, Humphreys SC. Whiplash: a review of a commonly misunderstood injury. Am J Med 2001;110:651-6.

5. Freeman MD. A review and methodologic critique of the literature refuting whiplash syndrome. Spine 1999;24:86-98.

6. Barnsley L, Lord SM, Bogduk N. Whiplash injury. Pain 1994;58: 283-307.

7. Grauer JN, Panjabi MM, et al. Whiplash produces an S-shaped curvature of the neck with hyperextension at lower levels. Spine 1997;22:2489-94.

8. Cassidy JDDC, et al. Effect of eliminating compensation for pain and suffering on the outcome of insurance claims for whiplash injury. N Engl J Med 2000;342:1179-86.

9. Rodriquez AA, Barr KP, Burns SP. Whiplash: pathophysiology, diagnosis, treatment, and prognosis. Muscle Nerve 2004;29:76881.

10. Van Geothem JW, et al. Whiplash injuries: is there a role for imaging? Eur J Radiol 1996;22:30-37.

11. Ronnen HR, de Korte PJ, et al. Acute whiplash injury: is there a role for mr imaging? - a prospective study of 100 patients. Radiology 1996;201 1:93-6.

12. Petterson K, et al. Disc pathology after whiplash injury: a prospective magnetic resonance imaging and clinical investigation. Spine 1997;22:283-7.

13. Borchegrevnik GE, Kaasa A, McDonagh D, et al. Acute treatment of whiplash neck sprain injuries. Spine 1998;23:25-31.

14. Rosenfeld M, Seferiadis A, Carlsson J, Gunnarsson R. Active intervention in patient with whiplash-associated disorder improves long-term prognosis. Spine 2003;28:2491-8.

15. Petterson K, Toolanen G. High-dose methylprednisolone prevents extensive sick leave after whiplash injury. a prospective, randomised, double-blind study. Spine 1998;23:984-9.

16. Vendrig AA, van Akkerveeken PF, McWhorter KR. Results of a multimodal treatment program for patients with chronic symptoms after a whiplash injury of the neck. Spine 2000;25:238-44.

17. Bunketorp L, Lindh M, Carlsson J, Stene-Victorin E. The perception of pain and pain related cognition in subacute whiplashassociated disorders: its influence on prolonged disability. Disabil Rehabil 2006;28:271-9.

18. Prushansky T, Pevzner E, Gordon C, Dvir Z. Cervical radiofrequency neurotomy in patients with chronic whiplash: a study of multiple outcome measures. J Neurosurg 2006;4:365-73.

19. Dufton JA, et al. Prognostic factors associated with minimal improvement following acute whiplash-associated disorders. Spine 2006;20:E759-65.

20. Nyunt BA. Unrecognized fracture through the base of superior articular facet of cervical spine presenting with transient tetraparesis. Injury 1995;8:563-4.

21. Renaudin J, Snyder M. Chip fracture through the superior articular facet with compressive cervical radiculopathy. J Trauma 1978;18:66-7. 